\title{
The Economics of International Refugee Law
}

\author{
Ryan Bubb, Michael Kremer, and David I. Levine
}

ABSTRACT: We model the current system of refugee protection as a contract that bound states to provide a more efficient level of the public good of refugee protection. We show how the screening problem caused by economic migration has strengthened states' incentives to shade on their obligations under the 1951 Convention, resulting in more refoulement of refugees to their place of persecution. We also model reform schemes in which wealthy states pay poorer states to host refugees. A system that transfers refugee claimants from wealthy states to poorer states could ameliorate the screening problem by inducing self-selection among refugee claimants but would also create negative externalities for third countries. We argue that reforms in which wealthy states paid poorer states to resettle refugees from other poorer states would be more efficient than current refugee policies that focus on providing aid in refugee camps and resettling refugees from camps to wealthy states.

Keywords: Refugees, International Law, International Migration, 1951 Convention JEL Classifications: F22, H41, H56, H87, J61, K33, O15, O19.

May 7, 2009

\footnotetext{
${ }^{*}$ Ryan Bubb is a doctoral candidate in the Department of Economics, Harvard University, and Terence M. Considine Fellow in Law and Economics at Harvard Law School. Michael Kremer is a professor in the Department of Economics, Harvard University. David Levine is a professor at the Walter A. Haas School of Business, University of California, Berkeley. We are grateful to Daniel Carvalho, Louis Kaplow, Alex Kaufman, Devra Moehler, Sendhil Mullainathan, Susan Rose-Ackerman, Holger Spamann, and participants in the American Law and Economics Association 2007 Annual Meeting, the 2007 Northeastern Universities Development Conference, and the Law and Economics Seminar at Harvard Law School for helpful comments. Bubb acknowledges financial support from the John M. Olin Center for Law, Economics and Business at Harvard Law School. Email: ryanbubb@fas.harvard.edu, mkremer@ fas.harvard.edu, levine@ haas.berkeley.edu
} 


\section{INTRODUCTION}

The 1951 Convention Relating to the Status of Refugees" 1 requires states to protect refugees that enter their territory. However, faced with increasing economic migration, in recent years states have made it more difficult for migrants to successfully apply for refugee status. In the hope of improving the international system of refugee protection, several reform schemes have been proposed, which we refer to as "transfer systems," in which refugees are transferred from the state to which they initially travel to another state in return for some payment to the host state. The aim of this paper is to provide a positive model that explains the evolution of international refugee law and to analyze transfer system-based reforms.

We model the current system of refugee protection based on the 1951 Convention as a Pareto improving contract that bound states to provide a more efficient level of the global public good of refugee protection. The increase in economic migration since the 1951 Convention was adopted has created a screening problem for host states, which have difficulty distinguishing between refugees and those who migrate in search of economic opportunities. We show how this screening problem in turn has strengthened host states' incentives to shade on the performance of their obligations under the 1951 Convention by increasing the standards of proof of their refugee status determination procedures, resulting in more false negatives and refoulement of refugees to their place of persecution. Moreover, the choice of standard of proof can exhibit strategic complementarity; as more states use a high standard of proof, the best response of other states may be to increase their standards of proof.

In our analysis of transfer systems, we distinguish between two different types of transfers: "north-to-south" transfers of refugees from wealthy states to poorer host states and "south-tosouth" transfers between poorer host states. We show that, although north-to-south transfer systembased reform schemes could ameliorate the screening problem by inducing self-selection among those who claim refugee status and result in increased protection of refugees, decentralized deals along these lines create negative externalities for third countries because fewer refugees apply to wealthy states likely to transfer them to a poorer state. In general equilibrium these reforms, while ${ }^{1}$ Convention Relating to the Status of Refugees, July 28, 1951, 189 U.N.T.S. 137 [hereinafter 1951 Convention]. 
increasing the number of refugees protected, could make some developing countries worse-off by increasing their burden of hosting refugees without fully compensating them for their increased costs. In contrast, a south-to-south transfer system is not subject to this externality problem, and we argue that such a system would be more efficient than current refugee policies that focus on providing aid in refugee camps and resettling a limited number of refugees from camps to wealthy states.

Section 2 of the paper provides background on the evolution of international refugee law; Section 3 presents a model that explains the formation of the current system of refugee protection; Section 4 considers how state compliance with the 1951 Convention is affected by economic migration; Section 5 models potential reform schemes; and Section 6 concludes.

\section{BACKGROUND}

The 1951 Convention was adopted in the aftermath of World War II to address the problem of large numbers of displaced people living in Europe outside of their country of origin, and was subsequently extended in 1967 to become a general regime for protecting those who cross national boundaries to avoid persecution. The 1951 Convention consists principally of a commitment by states not to return refugees that enter their territory to their country of persecution (non-refoulement). Under the Convention, then, the allocation of the burden of protecting refugees is determined largely by the migration choices of refugees. Furthermore, states themselves are responsible for determining which migrants are entitled to refugee status.

In recent years the 1951 Convention system has come under pressure as world inequality has increased, transportation costs have fallen, and wealthy states have faced increasing numbers of migrants claiming refugee status. The number of asylum applicants in Western Europe grew from 0.8 million in 1980-84 to 3.4 million in 1990-94 (Neumayer, 2005). In response, industrialized countries have implemented non-entreé policies that attempt to prevent migrants from entering

${ }^{2}$ The 1951 Convention was limited to refugees who acquired their refugee status "as a result of events occurring before 1 January 1951" but was effectively extended by the 1967 Protocol Relating to the Status of Refugees, Oct. 4, 1967, 606 U.N.T.S. 267 [hereinafter 1967 Protocol], which incorporated the substantive provisions of the 1951 Convention but lacked any temporal or geographic restriction on the definition of refugees. All references herein to the 1951 Convention should be understood to refer also to obligations under the 1967 Protocol. 
their territory and claiming refugee status under the Convention and have adopted stricter refugee status determination procedures (Keely \& Russell, 1994). Non-entreé policies typically involve intercepting refugees off-shore before they can apply. For example, the U.S. Coast Guard routinely interdicts Cuban and Haitian "boat people" and forcibly returns them to their country of origin. Furthermore, procedural reforms have made it more difficult for asylum seekers to successfully claim refugee status even when they reach developed states. For example, since the Dublin Convention $]^{7}$ came into force in 1997, asylum applicants in the EU must file their application in the country in which they first arrived. This procedural rule is intended to prevent "asylum shopping" by refugees. The U.S. tightened its refugee status determination procedures in a 1996 reform ${ }^{5}$ that provides for expedited removal proceedings in which immigration officers can order an alien removed without further hearing or review unless the alien states a fear of persecution or intent to

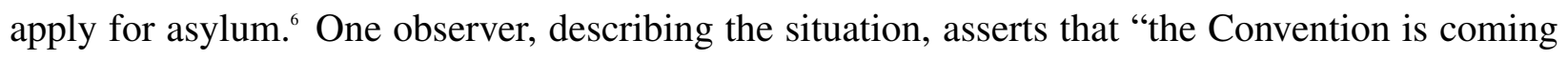
apart at the seams... Intercontinental travel has become easy... States say their asylum systems are being overwhelmed with this tangled mass of refugees and economic migrants and are urging a legal retrenchment" (Achiron, 2001).

While wealthy states have attempted to deflect those claiming refugee status, poorer states have become the primary hosts of refugees. Under the 1951 Convention, the burden of hosting refugees largely falls on states that are geographically proximate to refugee producers. At the end of 2005 , out of an estimated 8.4 million refugees worldwide, some 6.1 million resided in developing countries, principally in Africa, Central and Southeast Asia, and the Middle East (United Nations High

${ }^{3}$ When this policy was initiated under the Reagan administration, the Coast Guard conducted interviews of those intercepted and transported those with credible claims to refugee status to the U.S. while repatriating the rest. In 1992, however, facing a large influx of Haitians after a September 1991 coup deposed Haitian President Jean-Bertrand Aristide, the U.S. stopped conducting refugee screenings of intercepted Haitians and simply forcibly repatriated all of them. This interdiction policy was challenged in federal court, but the U.S. Supreme Court upheld the policy as consistent with both U.S. domestic law and the 1951 Convention. Sale v. Haitian Ctrs. Council, 113 S. Ct. 2549,509 U.S. 155 (1993).

${ }^{4}$ Convention Determining the State Responsible for Examining Applications for Asylum Lodged in One of the Member States of the European Communities, June 15, 1990, 30 I.L.M. 427.

IIlegal Immigration Reform and Immigrant Responsibility Act of 1996, Pub. L. No. 104-208, 110 Stat. 3009 (Sept. 30, 1996).

${ }^{\circ}$ INA $\S 235(\mathrm{~b})(1)(\mathrm{A}) \&(\mathrm{~B}), 8$ U.S.C. $§ 1225(\mathrm{~b})(1)(\mathrm{A}) \&(\mathrm{~B})$. This new policy results in the U.S. government taking less responsibility for identifying and protecting refugees; refugees who do not state a fear of persecution of their own accord at their initial interview can simply be refouled. 
Commissioner for Refugees, 2005). Poor countries deny many refugees the opportunity to integrate into their new national communities and "warehouse" many in large camps with limited economic opportunities (United Nations High Commissioner for Refugees, 2006).

Hathaway \& Neve (1997) and Schuck (1997) propose substantial reforms to the current system that combine increased commitments by developing countries to host refugees with payments from developed countries to compensate developing countries for the costs of refugee protection. The aim of these schemes is to reduce the incentive of economic migrants to fraudulently claim refugee status in wealthy countries by sending those who claim refugee status to poorer countries for protection, while at the same time improving protection in poorer countries through increased financing from wealthy countries. While it is difficult to accurately estimate the cost to industrialized countries of screening and hosting refugees, the United Nations High Commissioner for Refugees (UNHCR) has estimated the cost of administering asylum procedures and providing welfare benefits to refugee claimants in thirteen industrialized countries to be US \$7 billion in 1991 (United Nations High Commissioner for Refugees, 1995). Hathaway \& Neve (1997, p. 147) argue that the costs of payments from developed countries under their proposal would be offset by substantial reductions in these costs of administering the current refugee protection system.

\section{ExPlaining the 1951 Convention}

To explain the initial adoption of the 1951 Convention regime, we model refugee protection as a global public good using an extensive form game. In our model, we assume that political and ethnic persecution produces disutility for citizens of all states, but hosting refugees is costly to only the host state. This divergence in public and private benefits from hosting refugees results in free-riding and creates scope for a Pareto-improving contract under which states agree to host refugees in excess of the privately optimal number. We show that, in the absence of economic migration, the relatively simple regime of the 1951 Convention — "host all refugees who enter your country" - results in a more efficient level of the global public good of refugee protection. This result plausibly explains the widespread adoption of the 1951 Convention. 
3.1. Model setup. There are two regions, the north and the south. Each region has $L+1$ states, and each state has a continuum of citizens of unit mass. The set of states is denoted by $\left\{N_{0}, \ldots, N_{L}, S_{0}, \ldots, S_{L}\right\}$. The northern states are wealthy, which is reflected in their high wages, net of transfer payments and other benefits, $w_{N}$. The southern states are poor, each with wages $w_{S}<w_{N}$.

States $N_{0}$ and $S_{0}$ persecute a minority group with population of size $\lambda$ in each, costing group members $P$ utils if they remain in their country of origin.

The players in the model are all non-persecuting host states $\mathbb{H} \equiv\left\{N_{1}, \ldots, N_{L}, S_{1}, \ldots, S_{L}\right\}$ and the citizens of the persecuting states $N_{0}$ and $S_{0}$, the sets of which are denoted by $\mathbb{N}$ and $\mathbb{S}$, respectively, with $\mathbb{C} \equiv \mathbb{N} \cup \mathbb{S}$. As described in more detail below, host states in $\mathbb{H}$ choose refugee policies, and citizens in $\mathbb{C}$ then choose whether and where to migrate in response to those policies.

3.1.1. Host states. Assume that people in the host states are altruistic towards those who experience persecution, but also face costs of immigration. Potential reasons for such costs include xenophobic preferences, costs of redistribution in response to factor price changes caused by immigration, and any direct financial burdens imposed by immigrants $]^{7}$ We model the burden of immigration as simply an additively separable cost in host states' utility functions that is a function of the number of immigrants hosted, denoted by $B(\cdot)$, with $B^{\prime}(\cdot) \geq 0, B(0)=0, B^{\prime}(0)=0$, $B^{\prime \prime}(\cdot)>0.8$

Let $\beta$ represent the (assumed uniform) degree of altruism in countries' preferences, with $0<$ $\beta<<1$. For each refugee that avoids persecution, all host states get an additive altruistic utility benefit of $\beta P$.

Assume that host states do not observe the persecution status of migrants, but that they have access to a technology, referred to as a refugee status determination procedure, for testing whether

\footnotetext{
${ }^{7}$ Articles 23 and 24 of the Convention require states to accord refugees the same rights as nationals with respect to public relief and pensions.

${ }^{8}$ We are not making a normative claim about the costs and benefits of immigration, but rather a positive claim about the preferences that drive political decision-making in host states. The preferred amount of economic immigration in most countries is greater than zero, so the burden function $B(\cdot)$ should be thought of as the burden of receiving immigrants in excess of the amount that is privately optimal in the absence of altruistic refugee protection motives. We do not model explicitly these background economic migration flows. Receiving economic immigration through the refugee protection system is costly, since countries prefer to select economic migrants based on their country of origin and particular skill sets. The convexity of $B(\cdot)$ may be due to a marked increase in xenophobia as refugees become a sizeable and visible minority.
} 
a particular migrant faces persecution in his country of origin. The testing technology reveals evidence that a particular migrant has of his refugee status. A migrant can produce either weak or strong evidence, denoted by $e_{i} \in\{w, s\} \in \mathbb{R}^{2}$ with $s>w$. A fraction $\pi^{R}$ of citizens in each of $S_{0}$ and $N_{0}$ who are actually persecuted can produce strong evidence, while a fraction $\pi^{M}<\pi^{R}$ of those not actually persecuted can produce strong evidence (and the rest can produce only weak evidence). As detailed below, only some migrants are aware of their evidence type.

Assume, however, that country of origin is observable. Host states can use country of origin in forming beliefs about whether a migrant is a refugee.9 Since there are no altruistic benefits from admitting the non-persecuted, states would never admit any migrants from non-persecuting states, and so we omit any potential emigration from host states from the model.

3.1.2. Migrants. There are two potential motivations for citizens in persecuting states to migrate: (i) to avoid persecution; and (ii) to seek higher wages. We refer to migrants who are persecuted as "refugees" and to migrants who are not persecuted as "economic migrants."

Individuals' preferences for consumption of the single composite commodity are represented by $u(\cdot)$, with $u^{\prime}(\cdot)>0$. Thus, the utility citizens derive from consumption residing in a northern state, $u\left(w_{N}\right)$, is greater than that from residing in a southern state, $u\left(w_{S}\right)$.

Each person $i \in \mathbb{C}$ faces a dislocation cost of $d_{i}$ utils to relocating, because of, for example, psychic costs of being in a new culture and far from family, and these costs are distributed in the population according to the strictly increasing cumulative distribution function $G(\cdot)$ on the interval $[0, \bar{d}]$ (distributed independently of other characteristics). Furthermore, to travel between the south and the north costs an extra $J$ utils (the same amount for everybody) ${ }^{10}$

For now, as a rough approximation to the period in which the 1951 Convention was created, we consider the case in which transportation costs are high enough, and the wage differential is low

\footnotetext{
${ }^{9}$ Many countries, particularly those in Europe, routinely use country of origin as a (sometimes dispositive) indicator of refugee status. For example, under a 2004 reform to its asylum law, the U.K. has authorized the Home Secretary to publish a list of countries deemed "safe" and to decline to examine asylum applications from nationals of those countries. See Schedule 3 of the U.K. Asylum and Immigration (Treatment of Claimants, etc.) Act 2004, and Part 11, Section 345 of U.K. Immigration Rules.

${ }^{10}$ This embodies the assumption that travel between the north and south requires substantially more time and expense than travel within the north and south. Think of the north as Europe and the south as Sub-Saharan Africa.
} 
enough, that no non-persecuted person would choose to migrate, even if he would be admitted to a host state ${ }^{11}$ In particular, suppose:

Assumption 1. $u\left(w_{N}\right)-u\left(w_{S}\right)<J$ (no economic migration).

Furthermore, we assume that $P$ is a very large cost, so that persecuted citizens effectively have lexicographic preferences over host states: they prefer to migrate to the host state that offers the greatest probability of protection, regardless of region, and consider wages, dislocation costs, and transportation costs only when the probability of protection is equal between two or more host states 12

A fraction $\gamma$ of all citizens in $S_{0}$ and $N_{0}$ know their evidence type when making migration decisions, while the remaining fraction $1-\gamma$ do not. We refer to those who know their evidence type as "informed," and those who do not as "uninformed," and assume that whether a migrant is informed is distributed independently of his other characteristics (e.g., country of origin, evidence type, persecution status, etc.). This assumption captures the reality that some migrants have information about the strength of their claim, but not all migrants are perfectly informed $4^{13}$ We define the "type" of each citizen as $\theta_{i} \in\{w, s, \emptyset\}$ where $\theta_{i} \in\{w, s\}$ denotes an informed citizen with evidence $e_{i}=\theta_{i}$, and $\theta_{i}=\emptyset$ denotes an uninformed citizen. Citizens can condition their strategies on their type.

\subsubsection{Timing of the game and strategy sets of the players. Host states $j \in \mathbb{H}$ first simultaneously} choose whether to accede to the 1951 Convention. Let $t_{j}=1$ if host state $j$ accedes to the treaty, $t_{j}=0$ otherwise. The Convention comes into force if and only if all states accede ${ }^{14}$

\footnotetext{
${ }^{11}$ We relax this assumption in Section 4 below.

${ }^{12}$ In the analysis that follows, refugees will face only a discrete finite set of probabilities of being admitted to different host states: $0, \pi^{R}$ and 1 .

${ }^{13}$ Two polar cases are represented by $\gamma \in\{0,1\} \cdot \gamma=1$ represents the case in which all migrants know which host states they would be accepted by when deciding where to migrate. If this were the case, then in equilibrium no migrant would ever fail a refugee status determination since he would not have applied if he would fail. At the other extreme, with $\gamma=0$, all migrants with strong claims are unable to make different decisions than migrants with weak claims, which is also unrealistic. The assumption that the population is made up of a combination of citizens who are perfectly informed of their evidence type and citizens who are completely ignorant of their evidence type is a reduced form way to model tractably the fact that migrants are, on average, imperfectly informed of the strength of their refugee claim.

${ }^{14}$ It is not clear that this is the right way to model the choice to accede to the 1951 Convention. Under Article 43 of the Convention, the Convention enters into force following ratification by just six states. If all other $2 L-1$ host states
} 
If all host states join the Convention, then each state simultaneously chooses the standard of proof of its refugee status determination procedures, $p_{j} \in\{w, s\} \cdot p_{j}$ represents a cutoff such that, under the 1951 Convention, if an applicant for refugee status can produce evidence $e_{i} \geq p_{j}$, then the host state must admit the migrant. $\left.\right|^{1516}$ Denote the profile of all host states' choices as $p$.

By choosing the high standard of proof, $p_{j}=s$, a host state can exclude all migrants with $e_{i}=w$. However, if host state $j$ chooses the high standard of proof, it suffers a "shading cost" $K$ in its payoff function. $K$ captures in a reduced form way states' aversion to shading on the performance of their international obligations. The underlying reasons for these preferences, which result from details of international politics that are beyond the scope of this paper, are unmodeled ${ }^{17}$ However, host states may not withdraw from the Convention (or if you like, withdrawing is associated with a very large utility penalty) or set a $p_{j}>s$, and must admit all migrants who successfully meet their standard of proof. 18

We are essentially assuming a form of incomplete contracting. States are able to contract on the broad legal responsibility to avoid non-refoulement. Once they have acceded to the Convention, states effectively cannot outright withdraw or plainly breach the Convention. Under the Convention states must make judgments about the refugee status of migrants through appropriate legal procedures. However, the details of these refugee status determination procedures - namely, the

accede, then the remaining state would rather stay out and free ride on the hosting by others. And indeed, while some 146 states have acceded to the Convention, some states (perhaps most notably India) have still not done so. We assume this form of bargaining — everybody or nobody acceding — to simplify the analysis. If we used something other than a unanimity rule, the analysis would be similar, but as the number of states necessary for the Convention to come into force decreases, free-riding by states that stay out and enjoy the altruistic benefits of increased hosting by Convention states but bear none of the costs becomes harder to prevent.

${ }^{15}$ These assumptions roughly correspond to the actual Convention regime. The Convention only requires states to admit refugees and places on states the burden of determining refugee status. However, refugee status determinations typically turn on the testimony of the refugee claimant, and economic migrants have strong incentives to claim refugee status and lie about being persecuted, given the large cross-country disparities in economic opportunities. Thus refugee status determinations are imperfect.

${ }^{16}$ In an earlier version of the paper, host states formed beliefs about the refugee status of an applicant based on their evidence, and the standards of proof represented cutoffs of those beliefs, above which parties to the Convention were obligated to admit the applicant. The solution concept used was perfect Bayesian equilibrium. The results generated by this more micro-founded setup were the same as the present simpler model.

${ }^{17}$ For a review of explanations for the compliance of states with international law, see Raustiala \& Slaughter (2002).

${ }^{18}$ Article 44 of the Convention allows states to denounce the Convention and be released from their obligations under the Convention one year after denouncing it. However, no state has denounced the Convention, and it appears that withdrawing is in fact costly to states. 
standards of proof used, $p$ - are not perfectly contractible and states can choose their standard of proof. States have induced preferences (represented by the shading cost $K$ ) for choosing the more generous standard of proof after acceding to the Convention. $K$ measures the degree of contractibility of $p$. We refer to the subgame following all host states joining the Convention as the "Convention game."

If instead some host state does not join the Convention, each host state $j$ then simultaneously chooses the total number of migrants to admit, denoted by $A_{j} \in[0,2 \lambda] .^{19}$ If more than $A_{j}$ migrants then attempt to migrate to host state $j, A_{j}$ of them are admitted by lottery. Denote an entire profile of all host states' choices by $A$. We refer to the subgame following some country not joining the Convention as the "non-cooperative game."

After host states have chosen their refugee policies, citizens in the persecuting states choose whether and where to migrate. We will refer to subgames following host states' refugee policy choices as "migration subgames."

Our solution concept is subgame perfect equilibrium (SPE). Thus, in equilibrium, each citizen's migration choice following each potential set of refugee policy decisions by host states is a best response to other citizens' choices, and given citizens' strategies, each host state's refugee policy strategy is a best responses to other host states' strategies. We assume that if a type of migrant is indifferent among a set of optimal destination choices then he mixes between each host state with equal probability, and thus that migrant type is spread evenly across host states in that set.

3.2. First best for host states. We first define the first best for host states as the allocation of refugees that maximizes the sum of all host states' utility functions. ${ }^{20}$ The first best is thus the solution to:

$$
\max _{\left\{R_{j}\right\}_{j \in \mathbb{H}}}\left\{\sum_{j \in \mathbb{H}}\left[\beta P \sum_{k \in \mathbb{H}}\left(R_{k}\right)-B\left(R_{j}\right)\right]\right\}
$$

\footnotetext{
${ }^{19}$ Note that under Assumption 1, all migrants are refugees, and thus states learn no payoff-relevant information by submitting applicants to refugee status determination procedures in this subgame.

${ }^{20}$ We exclude the utility of economic migrants and refugees from this definition both to simplify algebra and to capture the idea that we are considering contracts among states and excluding the possibility of contracts between migrants and states. While it is not readily apparent to us why contracts between migrants and states are not feasible, given their rarity in the real world we think it is realistic to exclude them.
} 
subject to

$$
\sum_{j \in \mathbb{H}} R_{j} \leq 2 \lambda
$$

and appropriate non-negativity constraints, where $R_{j}$ denotes the number of refugees hosted by state $j \in \mathbb{H}$. In the solution, the marginal cost of hosting refugees is equated across states, which, given our assumption that states face the same burden function $B(\cdot)$, implies that each state hosts the same number of refugees: ${ }^{21}$

$$
\forall j, k, R_{j}^{f b}=R_{k}^{f b} \equiv R^{f b}
$$

Depending on the parameters, the first best may or may not entail offering asylum to all who are persecuted. We will focus on the case in which the first best is the corner solution in which all refugees are protected. To guarantee this, throughout we assume

Assumption 2. $2 L \beta P>B^{\prime}\left(\frac{\lambda}{L}\right)$.

With this assumption, we have the following result.

Lemma 1. Under Assumption 2, in the first best all persecuted people are hosted $\left(R^{f b}=\frac{\lambda}{L}\right)$.

Proof. Suppose not. Then in the first best, the marginal social benefit of hosting an additional refugee is $2 L \beta P$ and the marginal social cost, given Assumption 2 and the convexity of $B(\cdot)$, is less than $2 L \beta P$ since some state must be hosting less than $\frac{\lambda}{L}$ refugees, so the maximand in (1) could be increased by increasing the number of refugees hosted - a contradiction.

3.3. The non-cooperative outcome. Consider the non-cooperative game, in which the 1951 Convention is not adopted. In this game, each host state $j$ simultaneously chooses how many migrants to admit, denoted by $A_{j}$. We focus on the case in which, optimizing individually, states would not want to host their pro rata share of refugees. In particular, throughout we assume

${ }^{21}$ If instead it is cheaper to host refugees in the south, then in the first best there would be more refugees hosted in each southern state than in each northern one. For more general forms of heterogeneity in burden functions across states, the condition is $B_{k}^{\prime}\left(R_{k}^{f b}\right)=B_{j}^{\prime}\left(R_{j}^{f b}\right) \forall k, j \in \mathbb{H}$. In the first best, more refugees are hosted where it is cheaper to host them. 
Assumption 3. $\beta P<B^{\prime}\left(\frac{\lambda}{L}\right)$.

With these assumptions, we have the following result.

Lemma 2. Under Assumptions 1,2 and 3 in any subgame perfect equilibrium of the non-cooperative game, states host fewer than the first best number of refugees, and some persecuted citizens in $N_{0}$ and $S_{0}$ remain in their country of origin.

Proof. Suppose not. Then there exists a SPE in which all $2 \lambda$ refugees migrate to and are hosted by the $2 L$ host states in $\mathbb{H}$, and therefore some host state $j$ must host at least $\frac{\lambda}{L}$ refugees. Host state $j$ 's payoff is then $2 \lambda \beta P-B\left(R_{j}\right)$, where $R_{j} \geq \frac{\lambda}{L}$ is the number of refugees hosted by $j$ in the SPE. However under Assumption 3 and given that $B^{\prime \prime}(\cdot)>0, j$ would gain by choosing some $A_{j}$ such that it hosts fewer than $\frac{\lambda}{L}$ migrants. A contradiction.

The inefficiency in the non-cooperative game results from the standard public goods problem — in the absence of a contract or other institution, states do not internalize the full social altruistic benefit they generate by hosting refugees yet bear the full social cost. In the resulting equilibrium, states under-provide refugee protection. The 1951 Convention, to which we now turn, was an attempt by states to solve this problem through contracting.

3.4. The 1951 Convention outcome. Consider now the Convention game following the decision by all states to accede to the 1951 Convention. In this game, host states in $\mathbb{H}$ simultaneously choose the standard of proof of their refugee status determination procedures, $p_{j} \in\{w, s\}$, and face a "shading cost" $K$ of choosing the high standard of proof, $p_{j}=s$. We now have the following result.

Lemma 3. Under Assumption 1 (no economic migration), if $K \geq B\left(\frac{\lambda}{L}\right)-B\left(\frac{\lambda \gamma \pi^{R}}{L}\right)$ then there is a subgame perfect equilibrium of the Convention game in which all states use the low standard of proof and all persecuted people are protected.

Proof is in the Appendix.

The reason we must have sufficiently high cost of shading $K$ to sustain this equilibrium in which all refugees are hosted is because each host state could reduce its burden of hosting by increasing its 
standard of proof, thereby deterring prospective refugees. Without some degree of contractibility of $p$ (represented by $K$ ), this would not be an equilibrium since an individual host state would prefer to free ride on the hosting efforts of others.

In the equilibrium with all host states choosing $p_{j}=w$, the first best under Assumption 2 is achieved, with refugees spread evenly across host states. However, if there is some heterogeneity in host states' costs of hosting refugees, then the Convention will not implement the first best. The first best is achieved by the 1951 Convention only if the migration destination choices of refugees happen to coincide with the cost-minimizing allocation of refugees to host states.

3.5. Equilibria of the entire game. Consider now the SPEs of the entire game. We have established that under Assumptions 1 (no economic migration), 2 and 3 , while in the first best all persecuted people are hosted, this is not achieved in the absence of the Convention. However, with sufficiently high costs of shading, all persecuted people are hosted under the Convention. Thus the Convention regime can be attractive to host states.

Proposition 1. Under Assumptions 1 (no economic migration), 2 and 3 if $K \geq B\left(\frac{\lambda}{L}\right)-B\left(\frac{\lambda \gamma \pi^{R}}{L}\right)$ then there exists a subgame perfect equilibrium in which all host states join the 1951 Convention and use the low standard of proof, and all persecuted people are protected.

\section{Proof is in the Appendix.}

Proposition 1 states that without economic migration, there can exist equilibria in which all states prefer the regime created by the 1951 Convention to the unregulated regime. In this subset of the parameter space, the 1951 Convention is a Pareto improving agreement among states to share the burden of hosting refugees, and given the choice between all countries acceding to the Convention and no Convention, all countries would be willing to accede without side payments. Because of the low wage differential and the high cost of moving between regions, the 1951 Convention is only applied to true refugees, and each country faces equal inward flows of refugees. Under these conditions, compliance with the 1951 Convention is relatively easy for states to monitor, and host states use the low standard of proof and do not shade on the performance of their obligations under the Convention since the reduction in hosting burden they could achieve by raising their standard 
of proof is less than their shading costs. Note that the simple rule - host all refugees that enter your borders and claim asylum — also economizes on administrative costs.

The subset of the parameter space considered here seems to us to be a rough approximation to the context in which the 1951 Convention was adopted, and our stylized model provides a formal explanation for why the 1951 Convention was created — it reduced free riding by states and increased the number of refugees protected to (closer to) the efficient level.

\section{EXPLAINING THE BREAKDOWN OF THE 1951 CONVENTION}

Since it was adopted in 1951, the Convention regime has become less attractive to wealthy states, which have made it increasingly difficult for refugees to claim their rights under the Convention. We consider now the effect of economic migration on state compliance with the 1951 Convention. We model the 1951 Convention as an incomplete contract - states are able to contract on the broad responsibility to have legal procedures in place to process refugee applications and to host applicants that are granted refugee status, but are unable to contract on details of their refugee status determination procedures. Economic migration can increase incentives for states to shade on the performance of their obligations under the Convention by increasing the standard of proof of their refugee status determination procedures. Moreover, as more states shade, it can become more attractive to other states to shade as well since they face larger flows of asylum applicants. For some parameter values, this strategic complementarity results in multiple equilibria, with both all states fully complying with the Convention, as well as all states shading on performance of their Convention obligations, being equilibria.

In this analysis, we focus attention on the Convention game. Consider the case in which transportation costs are low enough, and the wage differential is high enough, that some non-persecuted citizens from $S_{0}$ would choose to migrate north if they would be admitted to a host state. In particular, assume

Assumption 4. $u\left(w_{N}\right)-u\left(w_{S}\right)>J$ (economic migration). 
Define $\Delta u \equiv u\left(w_{N}\right)-u\left(w_{S}\right)$ as a measure of the strength of the economic incentive to migrate. As $\Delta u$ gets larger, more potential economic migrants (those with sufficiently low dislocation costs $d_{i}$ ) will want to migrate from $S_{0}$ to a northern host state.

As a simplification, we focus on symmetric SPEs, in which either all host states choose $p_{j}=w$ or all choose $p_{j}=s \cdot \sqrt{22}$ We then have our main result for the Convention game:

Proposition 2. Under Assumption 4 (economic migration), there exists a $\bar{K}$ and $\underline{K}$ such that

(1) There exists a SPE in which all host states use the low standard of proof if and only if $K \geq \underline{K}$

(2) There exists a SPE in which all host states use the high standard of proof if and only if $K \leq \bar{K}$

(3) For all $\Delta u \in(J, J+\bar{d}), \frac{\partial \underline{K}}{\partial \Delta u} \geq 0$

(4) If $L G^{\prime}(\Delta u-J) \geq \pi^{M} G^{\prime}\left(\Delta u-J / \pi^{M}\right)$ then for all $\Delta u \in(J, J+\bar{d})$, $\frac{\partial \bar{K}}{\partial \Delta u}>0$ (where it exists)

\section{Proof is in the Appendix.}

Parts (1) and (2) of the Proposition imply that, for sufficiently high values of the shading cost $K$, all host states using the low standard of proof is the unique symmetric equilibrium, even with economic migration. However, parts (3) and (4) state that as the wage gap between north and south increases, the level of $K$ required to make the low standard of proof an equilibrium increases. Furthermore, the level of $K$ below which all host states choosing the high standard of proof is an equilibrium also increases $\sqrt{23}$ As transportation costs fall and the wage differential between north and south increases, economic migrants begin to mix with refugees and the 1951 Convention is less attractive to states. The increase in states' burden of hosting migrants caused by an increase in

\footnotetext{
${ }^{22}$ Asymmetric equilibria certainly exist for some parameter values, in particular one in which all northern host states choose $p_{j}=s$, and all southern host states choose $p_{j}=w$ (which is perhaps a good approximation to the current refugee policies around the world). Similar results can be derived for these equilibria.

${ }^{23}$ The condition $L G^{\prime}(\Delta u-J)>\pi^{M} G^{\prime}\left(\Delta u-J / \pi^{M}\right)$ in part (4) of Proposition 2 is just a weak restriction requiring the density function $G^{\prime}(\cdot)$ to be sufficiently flat. The even weaker necessary and sufficient condition is that the expression given in (22) in the Appendix be positive. This condition only fails for extremely unusual density functions with a large spike right at $\Delta u-J / \pi^{M}$. We use the sufficient condition in our statement of Proposition 2 to make the Proposition easier for the reader to parse.
} 
the incentive for economic migration makes it more difficult to sustain the low standard of proof equilibrium, as states can save more on hosting costs by increasing their standard of proof. Our model thus shows how economic migration can lead to a partial breakdown of the Convention system. States' induced preferences for compliance with international law (represented in the model by $K$ ) may have been sufficient to support full compliance in the early years of the Convention regime when there was relatively little economic migration, but the subsequent increase in economic migration resulting from rising world inequality and falling transportation costs may have reduced state compliance with the Convention.

Furthermore, host states face strategic complementarity in their choice of whether to shade on performance of their obligations under the Convention. Consider first a strategy profile with economic migration in which all host states choose the low standard of proof. If one state deviates by increasing its standard of proof, then migrants travel in increased numbers to the other states, increasing their burden of hosting migrants and therefore their incentive to raise their standard of proof. Moreover, the pool of migrants going to other host states worsens in the sense of being composed of a higher proportion of economic migrants. This occurs since informed migrants with strong evidence, who are more likely to be refugees than the rest of the migrant population, continue to travel to the strict state, and the flow of migrants that are redirected from the strict state to other host states contains a smaller proportion of refugees than the proportion of refugees in the overall migrant flow. Choosing a high standard of proof is thus a "beggar thy neighbor" strategy, and makes other host states worse off.

Furthermore, as an immediate implication of Proposition 2, we have:

Corollary 1. If $\underline{K} \leq K \leq \bar{K}$, then both all host states using the low standard proof, and all using the high standard of proof, are SPEs.

For intermediate values of $K$, strategic complementarity can result in multiple equilibria, with both all northern states using the low standard of proof, and all northern states using the high standard of proof, being equilibria. In this area of the parameter space, if all other host states are using the low standard of proof, then the relatively small reduction in hosting costs that a host state 
would get from raising its standard of proof is smaller than the shading cost $K$. But if all other host states are using the high standard of proof, the large increase in hosting costs that a host state would get from lowering its standard of proof would be larger than the avoided shading cost $K$. Strategic complementarity can thus turn the old adage "two wrongs don't make a right" on its head. The first $2 L-1$ wrongs can indeed make the last wrong appealing, even when no country would prefer to be the first to unilaterally use a high standard of proof in its refugee status determination procedures.

\section{Potential Reforms to the International Refugee Protection System}

Given the inefficient outcomes that have resulted from increased economic migration and the consequent tightening of refugee status determinations, consideration of potential reforms to the 1951 Convention system is in order. The logic of the Coase theorem suggests that additional contracting among host states may result in a more efficient allocation of refugees than is achieved by the 1951 Convention system. In the high standard of proof equilibrium of the Convention game with economic migration characterized in Proposition 2 , fewer refugees are protected than in either the first best or the low standard of proof equilibrium. However, if the incentive for economic migration were somehow eliminated, the screening problem would disappear, potentially resulting in a higher level of refugee protection.

Host states would like to treat economic migrants and refugees differently, selecting economic migrants based on economic considerations such as skills and limiting the total amount of economic migration, while at the same time protecting all refugees from persecution. However, if refugees are accorded more generous treatment than economic migrants and refugee status is unobservable, this first best (from the perspective of host states) menu is not incentive compatible, and economic migrants have an incentive to falsely claim refugee status. From a mechanism design perspective, host states would like a mechanism that makes it unattractive to economic migrants to claim refugee status but does not deter persecuted people from seeking protection. 
One potential such mechanism is to impose a large income tax on refugees from poor states that are hosted in wealthy countries. $\stackrel{24}{ }^{24}$ If an income tax were levied on successful asylum claimants so as to make their after-tax income roughly the same as it would be in their country of origin, then the non-persecuted would have less incentive to falsely claim refugee status. However, such a tax would violate Article 29 of the Convention, which prohibits discriminatory taxation of refugees.

Another potential separating mechanism, which we focus on in this paper, is for northern states to send refugees they receive to southern states for protection. For such an arrangement to be individually rational for southern states, northern states may have to make payments to southern states to compensate them for their increased burden of hosting. We will refer to a system under which states transfer refugees that arrive in one state to another state for protection as a "transfer system."

Hathaway \& Neve (1997) and Schuck (1997) both propose transfer system-based reforms to the international refugee protection system. In the system proposed by Hathaway \& Neve (1997), states would form regional "interest-convergence groups" in which poorer states in a region would agree to host the majority of refugees produced in the region, and richer states in the region would agree to finance the costs of refugee protection incurred by those host states. Refugee claimants in the wealthier states would be transferred to safe, poorer countries for refugee status determination proceedings. This would eliminate the incentive of both refugees and economic migrants to seek asylum in wealthier countries, which would allow developed states to dismantle their current costly refugee status determination institutions and non-entreé policies.

Schuck (1997) proposes a similar system in which states would agree to quotas, based on national wealth or other criteria, for the number of refugees each is obligated to protect. Schuck's main innovation is to propose that states be allowed to trade their refugee quotas in a market, which would presumably result in an allocation of refugees similar to that envisioned by Hathaway and Neve.

\footnotetext{
${ }^{24}$ We are not arguing that such a tax would be a normatively attractive approach; we offer it simply as an example of an incentive compatible mechanism.
} 
While states have not implemented anything like the large-scale transfer systems proposed by Hathaway \& Neve (1997) and Schuck (1997), the United States and Australia recently entered into an informal bilateral agreement under which each will transfer a small number of refugees that apply for asylum in one country to the other country for resettlement. The goal of the program is to deter asylum seekers by sending them to a country far away with which they have few cultural links (Kralev, 2007).

Other variants of such reforms are conceivable as well. For example, refugees from developing countries who migrate to developed countries, rather than being entitled to remain in the developed country, could be given a voucher that entitles a country that accepts the refugee to a payment from an international fund. As a condition to receiving the voucher payment, the host country would have to provide the refugee with an internationally agreed-on set of rights, akin to the current rights provided refugees under the 1951 Convention. The payment could be set large enough to induce some set of host states to accept the refugee and to allow refugees some choice in where to move. Indeed, one can imagine a centralized market in refugee vouchers, similar to the quota market envisioned by Schuck (1997), in which prospective host countries would bid on the right to host refugees. Such a system could also reduce the incentive of economic migrants to claim refugee status if the winners of the bidding over vouchers were predominately developing countries, which presumably face lower costs of hosting refugees.

Modeling the details of any such reform proposals, and considering the myriad implementation issues that would beset them, awaits future work. For now, we use our positive model of international refugee law to analyze simple transfer systems. We distinguish between two types of transfers: North-to-south transfers in which a refugee claimant that travelled to a northern host country is sent to a southern country for hosting, and south-to-south transfers in which refugee claimants are transferred between southern host states. Our analysis yields several insights.

First, north-to-south refugee transfer systems reduce the incentive of economic migrants to apply for refugee status as refugees are now hosted in lower income countries. We argue that by 
inducing self-selection among those who apply for refugee status, such transfer systems could result in increased protection of refugees. Rich nations also benefit as the flow of economic migrants applying for refugee status is reduced.

However, we show that with a north-to-south transfer system in place, refugees will have no incentive to travel first to a wealthy state to apply for refugee status and instead will travel directly to a poor state for hosting. These changes in the migration destination choices of refugees are an externality of transfer system contracts, and poorer transferee states potentially face a prisoner's dilemma in which each may be willing to participate in such a system, but each may be better off if none of them participated.25 Whether a transfer system-based reform is Pareto improving among host states depends on whether poorer transferee states can bargain collectively for a level of payments from transferor states that fully compensates them for their increased costs of hosting.

Finally, we consider south-to-south transfers. While such transfers do not help ameliorate northern states' screening problem, they are also not subject to the negative externality to southern host states associated with north-to-south transfers. Furthermore, they are likely a more efficient way for northern states to reduce the social costs that result from the massing of refugees in the southern host states closest to the sources of refugee flows than are current policies.

5.1. Transfer system of individual northern state. We model north-to-south transfer systems using a modified version of the baseline Convention game model defined in Section 3.1. We assume, then, that all states have acceded to the Convention. We first consider the decision of an individual northern state to setup its own transfer system. Suppose that a single northern state $N_{k}$ could, prior to all states choosing their standards of proof $p$, offer a set of contracts to southern states defined by $\left\{\left(Q^{S_{j}}, T^{S_{j}}\right)\right\}_{j=1, \ldots, L}$, where $Q^{S_{j}}$ is the number of refugee transfer slots southern country $S_{j}$ provides to migrants from $S_{0}$ sent by $N_{k}$ in exchange for a payment $T^{S_{j}}$. Under the agreement, state $N_{k}$ can deport $Q^{S_{j}}$ migrants from $S_{0}$ whom it determines have refugee status to state $S_{j}$. Each southern state then simultaneously chooses whether to accept or reject its contract

\footnotetext{
${ }^{25}$ Similar prisoner's dilemmas arise in other areas of international law. For example, Bilateral Investment Treaties impose externalities on other states through their effect on foreign investment flows, and recipients of foreign investment may face a prisoner's dilemma in choosing whether to agree to BITs with source countries. See Guzman (1998) and Bubb \& Rose-Ackerman (2007).
} 
offer (for simplicity, without knowing the contracts offered to other southern host states). Any states that accept are paid their $T^{S_{j}}$ by $N_{k}$. Then, after migrants make their migration decisions, $N_{k}$ can transfer any southern migrant that passes its refugee status determination procedure to a southern state with open contracted-for transfer slots until all slots are filled. We restrict attention to Markov-perfect PBEs in which citizens' strategies are a function only of the state $p$ and the set of transfer system contracts and not the entire history of contract offers and rejections/acceptances by southern host states, and similarly host states' strategies specifying their standards of proof are a function of only the set of transfer system contracts. We refer to this game as the Individual Transfer System game.

We now have the following result:

Proposition 3. Under Assumption 4 (economic migration), there exists a $\bar{K}^{I T S}$ such that, if $K \leq$ $\bar{K}^{I T S}:$

(1) There exists a SPE of the baseline Convention game in which all host states use the high standard of proof.

(2) There exists a SPE of the Individual Transfer System game in which $N_{k}$ adopts a transfer system and hosts no southern migrants, all host states use the high standard of proof, and other northern states are made worse off than they are in a SPE of the baseline Convention game.

Proof is in the Appendix.

The northern state with the transfer system is made better off by using the transfer system because it deflects both economic migrants and southern refugees to other northern host states by making it less attractive as a migration destination. This individual transfer system is thus a "beggar thy neighbor" strategy for state $N_{k}$ in much the same way as increasing the standard of proof. Individual northern states thus have a strong incentive to enter into such contracts with southern states 26

\footnotetext{
${ }^{26}$ The rarity of transfer systems in the world is a puzzle. The explanation may be in part that, since transfer systems make refugees who would have been admitted to a wealthy state in the absence of the transfer system worse off, they are generally opposed by refugee advocates. See, e.g., $\frac{\text { Anker } \text { et al. }}{20}$ (1998).
} 
5.2. Global north-to-south transfer system. With $N_{K}$ 's transfer system in place, other northern states will have an even stronger incentive to follow suit as they are now hosting more migrants. There is thus strategic complementarity in creating north-to-south refugee transfer systems. Consider now a game in which all northern states simultaneously offer contracts to southern states $(Q, T) \equiv\left\{\left(Q_{N_{k}}^{S_{j}}, T_{N_{k}}^{S_{j}}\right)\right\}_{j, k=1, \ldots, L}$, where $Q_{N_{k}}^{S_{j}}$ is the number of refugee transfer slots southern country $S_{j}$ provides to migrants from $S_{0}$ sent by $N_{k}$ in exchange for a payment $T_{N_{k}}^{S_{j}}$. Each southern state can then accept or reject each individual contract. The game then proceeds as before, but after citizens make their migration choices, each northern state can transfer any southern migrants that pass its refugee status determination procedures to southern states with which it has unused contracted-for transfer slots. Again, we focus on Markov-perfect PBEs. We refer to this game as the Global Transfer System game.

We have the following result.

Proposition 4. (1) There exists a $\underline{K}^{G T S}<\underline{K}$ such that if $K \geq \underline{K}^{G T S}$ then an equilibrium of the Global Transfer System game exists in which all host states use the low standard of proof and all persecuted people are protected.

(2) If $K \geq \underline{K}$ then southern states are made worse off in this equilibrium of the Global Transfer System game than they are in an equilibrium of the baseline Convention game.

\section{Proof is in the Appendix}

Part (1) of the Proposition implies that for $\underline{\mathrm{K}}^{G T S} \leq K<\underline{\mathrm{K}}$, while without a north-to-south transfer system the low standard of proof equilibrium does not exist, it does exist with a global north-to-south transfer system in place, resulting in all persecuted people being protected. The reason a large-scale transfer system can result in the first-best level of refugee protection is that, by eliminating the economic incentive to migrate, the transfer system eliminates host states' screening problem. Migrants from poor countries that are fleeing persecution (i.e., refugees) would be willing to apply for refugee status in a developed country with a transfer system, since they would prefer being hosted in a relatively poor host state to which they would be transferred to remaining persecuted in their country of origin. In contrast, economic migrants have no incentive to falsely 
claim refugee status and instead would have incentives to apply to be admitted through the official channels for economic migration. This ability to treat economic migrants and refugees differently in an incentive compatible way is a virtue of a north-to-south refugee transfer system from the perspective of northern host states.

However, this may not be Pareto improving, even among host states, as the north-to-south transfer system also alters the migration destination choices of southern refugees. With a transfer system in place, southern refugees now migrate to southern host states directly, rather than first bearing the cost of migrating north and then being sent south via the transfer system, and the resulting increase in southern states' burden of hosting refugees may not be fully compensated by payments made by northern host states under the transfer system. Each southern host state's transfer system contracts thus impose externalities on other southern host states through their effect on the migration choices of southern refugees. Southern host states may face a prisoner's dilemma in which they would be better off if none of them signed onto transfer system contracts, but each host state individually has an incentive to sign onto transfer system contracts. If instead of a decentralized market of take-itor-leave-it offers to individual southern host states, there is a collective bargaining process among all states, then a Pareto-improving contract could emerge in which southern host states receive payments that do fully compensate them for their increased hosting costs.

This externality associated with north-to-south transfer systems has not been considered in the extant literature proposing transfer system-based reforms. In the proposal of Hathaway \& Neve (1997), host states would form "interest convergence groups" in which the "inner core" members, which are poorer states that are geographically proximate to the sources of refugees, agree to be the primary hosts of refugees, and the "outer core" members, which are wealthier states that are generally further away from refugee producers, agree to bear the bulk of the inner core members' hosting costs by making payments to inner core members. Outer core members would then transfer successful refugee claimants to inner core members for hosting. Hathaway and Neve make a normative argument about how the fiscal burden should be allocated, suggesting that it be based on GNP or each country's funding obligations to the United Nations. However, our positive analysis predicts that, due to the effect of the transfer system on the migration choices of refugees, the outer 
core members may be able to induce inner core members to participate in such a system at a level of payments that results in inner core members being made worse off. As migration flows change in response to the north-to-south transfer system and a new equilibrium is reached, most refugees may travel directly to inner core members, and outer core members will be able to reduce payments without inner core members terminating the arrangement, since any individual inner core member would receive similar refugee flows whether or not it remains part of the transfer system.

To avoid such a result, there would need to be a commitment to a particular rule for fiscal contributions from outer core members that is not subject to renegotiation. The approach proposed by Schuck (1997) may provide an institution which is less likely to result in contributions that fail to fully compensate developing countries for their increased costs of hosting. In particular, Schuck proposes that each host state be assigned a refugee protection quota based on its GNP or other measures of state capacity. States would then be allowed to trade their refugee protection obligations, with transferee states taking on some part of the transferor state's quota in exchange for a payment. Importantly, the obligation to bear the cost of protecting refugees in this system is disassociated from the migration choices of refugees. The externality in north-to-south transfer systems identified in our analysis above would thus not exist in Schuck's proposed system. The centralized nature of Schuck's approach is thus a virtue. ${ }^{27}$ It is critical, however, that this system of allocating quotas be contractible, and states not be able to renegotiate the allocation rule after a new migration equilibrium is reached.

Importantly, a north-to-south transfer system would increase the level of refugee protection but would result in some refugees losing the economic benefits of protection in the north. Refugees who would have been hosted in a developed state are made worse off ex post since they are now sent to (or go directly to) a southern host state for protection. Indeed, since in our model migrants get to choose which host state to migrate to, interpreted literally our model implies that the transfer system makes all migrants weakly worse off in an ex ante sense since it effectively removes

\footnotetext{
${ }^{27}$ Hathaway and Neve's proposal could potentially also be made robust to this externality problem if some burden sharing rule could truly be committed to.
} 
northern host states from their choice set. In the equilibrium under the transfer system, no southern migrants attempt to migrate north.

However, in reality some refugees would continue to travel to host states in the north even with a north-to-south transfer system in place, as refugees' destination choices are often constrained and affected by random factors. Without the transfer system in place, some of these refugees' claims for refugee status would have been rejected, and they would have been sent back to be persecuted in their country of origin, while instead the transfer system results in these refugees being sent to southern host states for protection. These refugees are made better off by the transfer system in an ex ante sense. Furthermore, the refugees who currently choose to risk applying in the north and are denied refugee status and are refouled are made better off in an ex post sense by a transfer system, as instead they are protected in the south. The transfer system results in a reduction in the number of false negatives, which increases the overall number of refugees protected.

Finally, economic migrants who, in the absence of a north-to-south transfer system, would have successfully claimed refugee status in a developed state are made worse off by the transfer system.

Our simple model sheds light on the costs and benefits of a north-to-south refugee transfer system. Furthermore, it highlights the implications of the bargaining process among states for determining the distributive consequences of a transfer system. While our analysis does not yield any unambiguous normative conclusions about such transfer systems, it illuminates some of the tradeoffs facing states in adopting such a system.

5.3. South-to-south transfers. In the model above we assume that a set of migrants who are indifferent among several hosts spread themselves evenly across those hosts. It is straightforward to see what happens if we were to enrich the model slightly so there were migration costs within the south that were high relative to refugees' ability to pay. Now southern refugees would concentrate in their nearest neighbor. Under the 1951 Convention that neighbor has an obligation to host all refugees who arrive. In the model, we assume that each host state has an identical convex burden function such that the efficient allocation of refugees is to spread them equally across host states. Thus the massing of refugees in host states near the sources of refugees is inefficient. 
More generally, the first best is achieved by the 1951 Convention only if the migration destination choices of refugees happen to coincide with the cost-minimizing allocation of refugees to host states, which seems unlikely to be the case.

Moving from the model to recent history, concentrations of refugees often cause two additional problems besides the (often large) costs to the host. First, refugees are typically concentrated in refugee camps, often with terrible conditions and usually with limited or no rights to work in the host nation. Both refugees and (less directly) altruistic citizens in other nations suffer from this outcome. The confinement of refugees to camps probably reflects the convexity of the burden function - facing a smaller flow, these host states may be willing to provide refugees the right to integrate into their country. Second, concentrations of refugees can also contribute to the violence that resulted in refugee flows in the first place. For example, the Taliban government was born in the madrassahs of Afghan refugee camps in Pakistan (Moore, 2001), and those camps continued to provide soldiers for the Taliban in the war against the United States and its allies (Baldauf \& Tohid, 2003). Similarly, concentrations of Rwandan refugees in the Congo led to a bloody civil war as the Rwandan government sponsored Congolese rebel groups to attack them (Polgreen, 2007).

Northern states currently follow two policies related to these concentrations of refugees. First, the international community currently provides assistance to refugees in camps through, for example, the UNHCR. Second, some northern states, especially the United States, Great Britain, and Australia, participate in a resettlement program with the UNHCR in which they admit some refugees currently residing in refugee camps. These expenditures indicate that northern states find some altruistic benefits to assisting such concentrations of refugees in the south.

An alternative policy by which northern states could reduce the social costs associated with refugee concentrations in the south would be for them to compensate nearby southern host states that accept refugees and accord them certain rights, such as allowing them to work and to move freely within the host country. Such a south-to-south transfer system is part of the policy reform envisioned by Hathaway \& Neve (1997) (along with north-to-south transfers).

Subsidizing a south-to-south transfer system would be a more efficient way for northern states to reduce the social costs from current concentrations of refugees in particular southern host states 
than either paying for assistance to refugees concentrated in such camps or resettling them in northern host states. It seems likely that it is more costly for northern host states to resettle a refugee from a camp to its own territory than it would be for a nearby southern host state to resettle the refugee. If so, then there is surplus to be had from a contract in which the northern state pays such a southern host state to resettle the refugee. For a fixed resettlement budget, a northern host state could resettle more refugees through such south-to-south transfers than from taking in resettlement refugees itself. Furthermore, while providing aid to camps with large concentrations of refugees certainly provides some benefits to refugees, northern states may get more altruistic bang for their buck by concentrating their resources on resettlement under a south-to-south transfer system.

Importantly, an agreement for south-south refugee transfers would not have the possible negative externality of refugee transfers from the north to the south described in section 5.2 (where transfers from the north to the south discourage refugees from seeking protection in the north and, thus, can reduce payments southern states receive for hosting refugees).

\section{Conclusion}

While the 1951 Convention may have worked well in the past, the subsequent increase in economic migration resulting from falling transportation costs and increasing inequality has resulted in efforts by states to avoid their obligations under the Convention. Our model provides a formal account of this process.

One potential reform suggested by our analysis is to place the responsibility for refugee status determinations with the UNHCR. By centralizing the responsibility for recognizing refugees as such, states would no longer have the ability to shade on their obligations under the Convention by increasing the standards of proof of their refugee status determination procedures. Given that the current decentralized system results in less than socially optimal refugee protection, states party to the Convention may be willing to renegotiate this aspect of the international refugee protection system and thereby increase the number of refugees protected.

Our analysis of refugee transfer systems makes clear that, while such reforms could help ameliorate host states' screening problem and increase the number of persecuted people who are given 
refuge, such reforms do not make all potential migrants and host states better off. First, a north-tosouth transfer system clearly make economic migrants and some refugees worse off by closing off the refugee system as a route to better economic opportunities. Second, and less obviously, northto-south transfer systems may make poorer transferee states worse off, despite payments from transferor states that make it individually rational for transferee states to participate in such a system. Transfer systems such as the one recently consummated by the United States and Australia impose externalities on other states through their effects on the destination choices of migrants. Finally, a south-to-south transfer system avoids this externality problem, and subsidizing such transfers would be more efficient than current policies used by northern states to reduce the social costs caused by concentrations of refugees in certain southern host states.

\section{APPENDIX}

Proof of Lemma 3. In the proposed equilibrium, all host states choose $p_{j}=w$, and thus admit all migrants who apply for refugee status.

Migration decisions. Under Assumption 1, there is no economic migration, so all migrants are refugees and stay within their region. Furthermore, since $P$ is very large, all persecuted people will migrate. We assumed that whenever citizens are indifferent among a set of host state destinations, they mix between each with equal probability. Thus, by the law of large numbers, migrants are spread evenly across host states in this equilibrium.

Deviations by host states. In the proposed equilibrium, all migrants are hosted, and each host state receives the payoff:

$$
U_{j}(p=w)=2 \lambda \beta P-B\left(\frac{\lambda}{L}\right)
$$

Consider whether a host state $j$ would prefer to deviate by choosing $p_{j}=s$. Such a host state would now receive only informed migrants with $e_{i}=s$ from their region, since uninformed migrants and informed migrants with $e_{i}=w$ would prefer to go to states with $p_{k}=w$ where they will be admitted for sure. This deviation thus reduces state $j$ 's burden of hosting, but it would incur the shading cost $K$, yielding a payoff:

$$
U\left(p_{j}=s, p_{-j}=w\right)=2 \lambda \beta P-B\left(\frac{\lambda \gamma \pi^{R}}{L}\right)-K
$$

This deviation is not profitable, and the proposed equilibrium is indeed a SPE, if and only if

$$
K \geq B\left(\frac{\lambda}{L}\right)-B\left(\frac{\lambda \gamma \pi^{R}}{L}\right)
$$


Proof of Proposition 1, In the proposed equilibrium, all host states accede to the Convention. Lemma 3 states that under our assumptions, there exists a SPE of the Convention game in which all refugees are hosted. Each host state's payoff in such an equilibrium is

$$
U(p=w)=2 \lambda \beta P-B\left(\frac{\lambda}{L}\right)
$$

Consider now whether any host state has an incentive to deviate by not acceding to the Convention. First note that, if less than a total of $\lambda$ migrant slots are offered by host states in each region, then all of those slots will be filled by refugees. Assume for the moment that host states will receive as many refugees as they choose to admit. Each host state's choice of $A_{j}$ then solves

$$
\max _{A_{j}}\left\{\beta P \sum_{k \in \mathbb{H}}\left(A_{k}\right)-B\left(A_{j}\right)\right\}
$$

Assuming an interior solution, the solution satisfies, $\forall j \in \mathbb{H}$,

$$
B^{\prime}\left(A_{j}^{*}\right)=\beta P
$$

By Lemma 2 we know that $A_{j}^{*}<\lambda / L$, so under $A^{*}$, in each region fewer than $\lambda$ migrants slots will be offered by host states. Thus all host states choosing $A_{j}^{*}$ represents an equilibrium of the noncooperative game. Host states' payoffs in such an equilibrium of the non-cooperative game are

$$
U_{j}\left(A^{*}\right)=\beta P \sum_{k \in \mathbb{H}}\left(A_{k}^{*}\right)-B\left(A_{j}^{*}\right)
$$

Under Assumption 2 the equilibrium payoffs under the Convention given in (7) exceed the noncooperative payoffs given in (10), and so no host state has an incentive to deviate by not acceding to the Convention.

Proof of Proposition 2. Consider first the strategy profile $p=w$ in which all host states choose $p_{j}=w$. In the migration subgame that follows, non-persecuted citizens from $S_{0}$ will migrate north if $\Delta u-d_{i}>J$. The total number of economic migrants is thus $(1-\lambda) G(\Delta u-J)$. By Assumption 4. all persecuted people prefer to migrate to a northern host state rather than to a southern state. Northern and southern host states' payoffs are thus:

$$
\begin{gathered}
U_{N}(p=w)=2 \lambda \beta P-B\left(\frac{1}{L}(2 \lambda+(1-\lambda) G(\Delta u-J))\right) \\
U_{S}(p=w)=2 \lambda \beta P
\end{gathered}
$$

Southern host states have no incentive to deviate to $p_{j}=s$ since they would then bear the shading cost $K$ but get no benefit. If a northern host state deviated to $p_{N_{j}}=s$, it would receive only (its pro rata share of) informed migrants with $e_{i}=s$. Its payoff would then be:

$$
U_{N_{j}}\left(p_{N_{j}}=s ; p_{-N_{j}}=w\right)=2 \lambda \beta P-B\left(\frac{1}{L} \gamma\left(\pi^{R} 2 \lambda+(1-\lambda) \pi^{M} G(\Delta u-J)\right)\right)-K
$$

Thus, $p=w$ is an SPE if and only if this is not a profitable deviation, or:

$$
K \geq \underline{\mathrm{K}} \equiv B\left(\frac{1}{L}(2 \lambda+(1-\lambda) G(\Delta u-J))\right)-B\left(\frac{1}{L} \gamma\left(\pi^{R} 2 \lambda+(1-\lambda) \pi^{M} G(\Delta u-J)\right)\right)
$$

Consider now the strategy profile $p=s$ in which all host states choose the high standard of proof. Informed persecuted citizens from $S_{0}$ migrate north if $e_{i}=s$, and uninformed persecuted citizens from $S_{0}$ attempt to migrate north if $\pi^{R} \Delta u>J$; otherwise, they migrate to a southern 
host state. Informed non-persecuted citizens from $S_{0}$ migrate north if $e_{i}=s$ and $d_{i}<\Delta u-J$. Uninformed non-persecuted citizens from $S_{0}$ attempt to migrate north if $d_{i}<\Delta u-J / \pi^{M}$. All persecuted citizens in $N_{0}$ attempt to migrate to a northern host state. Northern and southern host states' payoffs are:

$$
\begin{gathered}
U_{N}(p=s)=\pi^{R} 2 \lambda \beta P-K \\
-B\left(\frac{1}{L}\left(\pi^{R} \lambda\left[2-(1-\gamma) I_{\left\{\pi^{R} \Delta u<J\right\}}\right]+\pi^{M}(1-\lambda)\left[\gamma G(\Delta u-J)+(1-\gamma) G\left(\Delta u-J / \pi^{M}\right)\right]\right)\right) \\
U_{S}(p=s)=\pi^{R} 2 \lambda \beta P-B\left(I_{\left\{\pi^{R} \Delta u<J\right\}} \frac{\pi^{R} \lambda}{L}(1-\gamma)\right)-K
\end{gathered}
$$

If northern state $N_{j}$ deviates to $p_{N_{j}}=w$, it will receive all uninformed migrants, all informed refugees with $e_{i}=w$, and its pro rata share of informed migrants with $e_{i}=s$. Its payoff would be:

$$
\begin{aligned}
& U_{N_{j}}\left(p_{N_{j}}=w ; p_{-N_{j}}=s\right)=2 \lambda \beta P \\
& \quad-B\left(2 \lambda\left[\frac{\gamma \pi^{R}}{L}+1-\gamma \pi^{R}\right]+(1-\lambda) G(\Delta u-J)\left(\left[\frac{\gamma \pi^{M}}{L}+1-\gamma \pi^{M}\right]\right)\right.
\end{aligned}
$$

This will not be profitable if and only if

$$
\begin{aligned}
K & \leq \bar{K}_{N} \equiv \\
& B\left(2 \lambda\left[\frac{\gamma \pi^{R}}{L}+1-\gamma \pi^{R}\right]+(1-\lambda) G(\Delta u-J)\left(\left[\frac{\gamma \pi^{M}}{L}+1-\gamma \pi^{M}\right]\right)\right. \\
& -B\left(\frac{1}{L}\left(\pi^{R} \lambda\left[2-(1-\gamma) I_{\left\{\pi^{R} \Delta u<J\right\}}\right]+\pi^{M}(1-\lambda)\left[\gamma G(\Delta u-J)+(1-\gamma) G\left(\Delta u-J / \pi^{M}\right)\right]\right)\right) \\
& -2 \lambda \beta P\left(1-\pi^{R}\right)
\end{aligned}
$$

Consider now a deviation by a southern state $S_{j}$ to $p_{S_{j}}=w . S_{j}$ would then receive all uninformed refugees and all informed refugees with $e_{i}=w$. Its payoff would be:

$$
\begin{gathered}
U_{S_{j}}\left(p_{S_{j}}=w ; p_{-S_{j}}=s\right)=2 \lambda \beta P \\
-B\left(2 \lambda\left(1-\gamma \pi^{R}\right)\right)
\end{gathered}
$$

This will not be a profitable deviation if and only if

$$
\begin{aligned}
K<\bar{K}_{S} \equiv B & \left(2 \lambda\left(1-\gamma \pi^{R}\right)\right. \\
& -B\left(I_{\left\{\pi^{R} \Delta u<J\right\}} \frac{\pi^{R} \lambda}{L}(1-\gamma)\right)-2 \lambda \beta P\left(1-\pi^{R}\right)
\end{aligned}
$$

Thus, $p=s$ is an equilibrium if and only if $K<\bar{K} \equiv \min \left(\bar{K}_{N}, \bar{K}_{S}\right)$.

We have shown that there exists $\bar{K}$ and $\underline{\mathrm{K}}$ such that $K>\underline{\mathrm{K}} \Leftrightarrow p=w$ is a SPE and $K<\bar{K} \Leftrightarrow$ $p=s$ is a SPE. Observe that for some parameter values, $\bar{K}>\underline{\mathrm{K}}$, so that it is possible that both $p=w$ and $p=s$ are equilibria. 
To establish the comparative statics of $\underline{\mathrm{K}}$, we differentiate the expression for $\underline{\mathrm{K}}$ in $(14)$, yielding:

$$
\begin{aligned}
\frac{\partial \underline{\mathrm{K}}}{\partial \Delta u}= & \frac{1}{L}(1-\lambda) G^{\prime}(\Delta u-J) B^{\prime}\left(\frac{1}{L}(2 \lambda+(1-\lambda) G(\Delta u-J))\right) \\
& -\frac{\gamma \pi^{M}}{L}(1-\lambda) G^{\prime}(\Delta u-J) B^{\prime}\left(\frac{1}{L} \gamma\left(\pi^{R} 2 \lambda+(1-\lambda) \pi^{M} G(\Delta u-J)\right)\right.
\end{aligned}
$$

Note that, since $G^{\prime}(\cdot)>0$ and $B^{\prime \prime}(\cdot)>0$ by assumption, $\frac{\partial \underline{\mathrm{K}}}{\partial \Delta u}>0$.

To establish the comparative statics of $\bar{K}$, we consider how changes in $\Delta u$ affect both $\bar{K}^{N}$ and $\bar{K}^{S}$. We first note that at the point $\pi^{R} \Delta u=J, \frac{\partial \bar{K}^{N}}{\partial \Delta u}$ and $\frac{\partial \bar{K}^{S}}{\partial \Delta u}$ are undefined, since uninformed persecuted citizens switch from going south to going north as $\Delta u$ exceeds $J / \pi^{R}$, leading to a discontinuous change in both $\bar{K}^{N}$ and $\bar{K}^{S}$. For all other values of $\Delta u \in(J, J+\bar{d})$, we differentiate (18) and (20) yielding:

$$
\begin{aligned}
& \frac{\partial \bar{K}^{N}}{\partial \Delta u}=(1-\lambda)[ \\
& \pi^{M} G^{\prime}(\Delta u-J)\left(\frac{\gamma \pi^{M}}{L}+1-\gamma \pi^{M}\right) B^{\prime}\left(2 \lambda\left[\frac{\gamma \pi^{R}}{L}+1-\gamma \pi^{R}\right]+(1-\lambda) G(\Delta u-J)\left(\left[\frac{\gamma \pi^{M}}{L}+1-\gamma \pi^{M}\right]\right)\right) \\
& -\frac{1}{L}\left[\gamma G^{\prime}(\Delta u-J)+(1-\gamma) G^{\prime}\left(\Delta u-J / \pi^{M}\right)\right] . \\
& \left.B^{\prime}\left(\frac{1}{L}\left(\pi^{R} \lambda\left[2-(1-\gamma) I_{\left\{\pi^{R} \Delta u<J\right\}}\right]+\pi^{M}(1-\lambda)\left[\gamma G(\Delta u-J)+(1-\gamma) G\left(\Delta u-J / \pi^{M}\right)\right]\right)\right)\right] \\
& \text { (23) } \frac{\partial \bar{K}^{S}}{\Delta u}=0
\end{aligned}
$$

Since $B^{\prime \prime}(\cdot)>0$, the first $B^{\prime}(\cdot)$ term that appears in (22) is larger than the second $B^{\prime}(\cdot)$ term since it's argument is larger. Thus a sufficient condition for $\frac{\partial \bar{K}}{\Delta u}>0$ is

$$
\pi^{M} G^{\prime}(\Delta u-J)\left(\frac{\gamma \pi^{M}}{L}+1-\gamma \pi^{M}\right) \geq \frac{1}{L}\left[\gamma G^{\prime}(\Delta u-J)+(1-\gamma) G^{\prime}\left(\Delta u-J / \pi^{M}\right)\right]
$$

Sufficient for this condition to be true is the simpler condition given in Proposition 2.

Proof of Proposition 3. Denote $S_{j}$ 's strategy that specifies whether to accept or reject each potential offer by the function $r_{S_{j}}\left(Q^{S_{j}}, T^{S_{j}}\right)$, which is equal to 1 if $S_{j}$ accepts and 0 if it rejects (and denote the entire strategy profile by $r(Q, T))$. Denote the profile of resulting contracts by $(\hat{Q}, \hat{T})$ (with $\hat{Q}^{S_{j}}=0$ and $\hat{T}^{S_{j}}=0$ if $S_{j}$ rejects). Define the total number of transfer slots contracted for by $N_{k}$ as $n(\hat{Q}) \equiv \sum_{j=1}^{L} \hat{Q}_{S_{j}}$. Denote citizens' strategy profile as $a(\cdot, \theta, p, \hat{Q})$ and host states' strategy profile following transfer slot contracting as $p(\hat{Q})$.

Consider the Individual Transfer System game. We look for an equilibrium $a^{*}(\cdot, \theta, p, \hat{Q}), p^{*}(\hat{Q})$, and $\hat{Q}^{*}$ in which $n\left(\hat{Q}^{*}\right)>0$, no southern migrants travel to $N_{k}$, and $p^{*}(\hat{Q})=s \forall \hat{Q}$.

First, note that if $N_{k}$ contracts for any transfer slots, it is less attractive to potential southern migrants as a destination since migrants arriving in $N_{k}$ risk being deported south under the transfer system. If any individual migrant deviated from the equilibrium by migrating to $N_{k}$, he would be deported south and would thus bear the cost $J$ with no benefit. Thus, all southern migrants that in 
the baseline Convention game SPE (with $p=s$ ) were traveling to $N_{k}$ now travel to other northern states $N_{-k}$ in equal numbers to each following any $\hat{Q}$ such that $n(\hat{Q})>0$.

Next, suppose $N_{k}$ makes take-it-or-leave-it offers of $\left(Q^{*}, T^{*}\right)$ such that $Q_{S_{j}}^{*}=\epsilon>0$ and $T_{S_{j}}^{*}=0 \forall j=1, \ldots, L$. Each southern state $S_{j}$ is indifferent between accepting or rejecting its offer since it will not actually receive any migrants through the transfer system (since $N_{k}$ will not receive any southern migrants).

Now consider host states' choices of standard of proof. In our proposed equilibrium, northern host states without the transfer system, $N_{-k}$, receive the following payoff.

$$
\begin{gathered}
U_{N_{-k}}\left(a^{*}(\cdot, \theta, \hat{Q}, p), p^{*}, \hat{Q}^{*}, \hat{T}^{*}\right)=\pi^{R} 2 \lambda \beta P-K \\
-B\left(\frac{1}{L} \pi^{R} \lambda+\frac{1}{L-1}\left(\pi^{R} \lambda\left[1-(1-\gamma) I_{\left\{\pi^{R} \Delta u<J\right\}}\right]+\pi^{M}(1-\lambda)\left[\gamma G(\Delta u-J)+(1-\gamma) G\left(\Delta u-J / \pi^{M}\right)\right]\right)\right)
\end{gathered}
$$

Compared with their equilibrium payoffs in the absence of a transfer system, given in (15), they now bear higher hosting costs since they now host the migrants that $N_{k}$ would have hosted in the absence of the transfer system.

If northern state $N_{j} \neq N_{k}$ deviates to $p_{N_{j}}=w$, it will receive all uninformed migrants, all informed refugees with $e_{i}=w$, and its pro rata share of informed migrants with $e_{i}=s$. Its payoff would be:

$$
\begin{aligned}
U_{N_{j}}\left(a^{*}(\cdot, \theta, \hat{Q}, p),\right. & \left.\left(p_{N_{j}}=w ; p_{-N_{j}}^{*}\right), \hat{Q}^{*}, \hat{T}^{*}\right)=2 \lambda \beta P \\
& -B\left(\lambda\left[\frac{\gamma \pi^{R}}{L}+\frac{\gamma \pi^{R}}{L-1}+2\left(1-\gamma \pi^{R}\right)\right]+\left[\frac{\gamma \pi^{M}}{L}+1-\gamma \pi^{M}\right](1-\lambda) G(\Delta u-J)\right)
\end{aligned}
$$

This will not be profitable if and only if

$K \leq \bar{K}_{N}^{\prime} \equiv$

$$
\begin{aligned}
& B\left(\lambda\left[\frac{\gamma \pi^{R}}{L}+\frac{\gamma \pi^{R}}{L-1}+2\left(1-\gamma \pi^{R}\right)\right]+\left[\frac{\gamma \pi^{M}}{L}+1-\gamma \pi^{M}\right](1-\lambda) G(\Delta u-J)\right) \\
& -B\left(\frac{1}{L} \pi^{R} \lambda+\frac{1}{L-1}\left(\pi^{R} \lambda\left[1-(1-\gamma) I_{\left\{\pi^{R} \Delta u<J\right\}}\right]+\pi^{M}(1-\lambda)\left[\gamma G(\Delta u-J)+(1-\gamma) G\left(\Delta u-J / \pi^{M}\right)\right]\right)\right) \\
& -2 \lambda \beta P\left(1-\pi^{R}\right)
\end{aligned}
$$

$N_{k}$ 's equilibrium payoff is

$$
U_{N_{k}}\left(a^{*}(\cdot, \theta, \hat{Q}, p), p^{*}, \hat{Q}^{*}, \hat{T}^{*}\right)=\pi^{R} 2 \lambda \beta P-B\left(\frac{\pi^{R} \lambda}{L}\right)-K
$$

If $N_{k}$ deviated and chose $p=w$, it would then receive all uninformed migrants as well as all informed migrants with $e_{i}=w$. The number of migrants it would receive would outnumber the small $\epsilon$ of transfer slots for which it has contracted. It's payoff would be (ignoring the $\epsilon$ transferred migrants):

$U_{N_{k}}\left(a^{*}(\cdot, \theta, \hat{Q}, p),\left(p_{N_{k}}=w ; p_{-N_{k}}^{*}\right), \hat{Q}^{*}, \hat{T}^{*}\right)=2 \lambda \beta P-B\left(\frac{\pi^{R} \lambda}{L}+2 \lambda\left(1-\gamma \pi^{R}\right)+(1-\lambda) G(\Delta u-J)\left(1-\gamma \pi^{R}\right)\right)$ 
This will not be a profitable deviation if and only if (30)

$K \leq \bar{K}_{N}^{\prime \prime} \equiv B\left(\frac{\pi^{R} \lambda}{L}+2 \lambda\left(1-\gamma \pi^{R}\right)+(1-\lambda) G(\Delta u-J)\left(1-\gamma \pi^{M}\right)\right)-B\left(\frac{\pi^{R} \lambda}{L}\right)-2 \lambda \beta P\left(1-\pi^{R}\right)$

Consider now a deviation by $N_{k}$ in which it sets $p_{N_{k}}=w$ and purchases enough transfer slots, spread evenly across southern states, to transfer all southern migrants that it receives. It would then receive a total of $\lambda\left(1-\gamma \pi^{R}\right)+(1-\lambda) G(\Delta u-J)\left(1-\gamma \pi^{R}\right)$ southern migrants. To induce a southern state to agree to host its pro rata share of these migrants, $Q^{S_{j}^{\prime}}=\frac{1}{L}\left[\lambda\left(1-\gamma \pi^{R}\right)+(1-\lambda) G(\Delta u-\right.$ $\left.J)\left(1-\gamma \pi^{R}\right)\right], N_{k}$ would have to offer a $T^{S_{j}^{\prime}}=B\left(\frac{1}{L}\left[\lambda\left(1-\gamma \pi^{R}\right)+(1-\lambda) G(\Delta u-J)\left(1-\gamma \pi^{R}\right)\right]\right)$. $N_{k}$ 's payoff would then be

$$
\begin{aligned}
& U_{N_{k}}\left(a^{*}(\cdot, \theta, \hat{Q}, p),\left(p_{N_{k}}=w ; p_{-N_{k}}^{*}\right), \hat{Q}^{S_{j}^{\prime}}, \hat{T}^{S_{j}^{\prime}}\right)= \\
& 2 \lambda \beta P-B\left(\lambda\left(1-\gamma \pi^{R}\right)+\lambda \frac{\gamma \pi^{R}}{L}\right)-L B\left(\frac{1}{L}\left[\lambda\left(1-\gamma \pi^{R}\right)+(1-\lambda) G(\Delta u-J)\left(1-\gamma \pi^{R}\right)\right]\right)
\end{aligned}
$$

This will not be a profitable deviation if and only if

$$
\begin{aligned}
K \leq & \bar{K}_{N}^{\prime \prime \prime} \equiv \\
& B\left(\lambda\left(1-\gamma \pi^{R}\right)+\lambda \frac{\gamma \pi^{R}}{L}\right)+L B\left(\frac{1}{L}\left[\lambda\left(1-\gamma \pi^{R}\right)+(1-\lambda) G(\Delta u-J)\left(1-\gamma \pi^{R}\right)\right]\right) \\
& -B\left(\frac{\pi^{R} \lambda}{L}\right)-2 \lambda \beta P\left(1-\pi^{R}\right)
\end{aligned}
$$

The condition for $K$ such that no southern states has an incentive to deviate from $p=s$ is the same as in the proof of Proposition 2, $K \leq \bar{K}_{S}$. Thus, let $\bar{K}^{I T S}=\min \left(\bar{K}_{N}, \bar{K}_{N}^{\prime}, \bar{K}_{N}^{\prime \prime}, \bar{K}_{N}^{\prime \prime \prime}, \bar{K}_{S}\right)$. $K \leq \bar{K}^{I T S}$ is a sufficient condition for $p=s$ to be a SPE in both the baseline Convention game and the Individual Transfer System game.

Furthermore, let equilibrium strategies be such that if $N_{k}$ offered contracts such that $n(\hat{Q})=0$, the equilibrium identified in the proof of Proposition 2(2) above would result, giving $N_{k}$ the payoff given in (15). We can see that $N_{k}$ is made better off by its transfer system, since it hosts fewer migrants. $N_{k}$ is indifferent between any $\hat{Q}$ such that $n(\hat{Q})>0$ since migrant behavior is the same following any such choices. And clearly $N_{k}$ is made worse off by choosing any $T_{S_{j}}>0$.

Proof of Proposition 4. Denote $S_{j}$ 's strategy that specifies whether to accept or reject by the vector-valued function $\mathbf{r}^{S_{j}}\left(Q^{S_{j}}, T^{S_{j}}\right)$ where $\left(Q^{S_{j}}, T^{S_{j}}\right)$ is the vector of contract offers made to $S_{j}$, and the $k$-th element of $\mathbf{r}^{S_{j}}\left(Q^{S_{j}}, T^{S_{j}}\right)$ is equal to 1 if $S_{j}$ accepts the contract offered by $N_{k}$ and is equal to 0 if it rejects. Denote the entire profile of southern host state strategies by $\mathbf{r} \equiv$ $\left\{\mathbf{r}^{S_{j}}\left(Q^{S_{j}}, T^{S_{j}}\right)\right\}_{j=1, \ldots, L}$. Denote the the resulting contract between $S_{j}$ and $N_{k}$ by $\left(\hat{Q}_{N_{k}}^{S_{j}}, \hat{T}_{N_{k}}^{S_{j}}\right)$, and let $(\hat{Q}, \hat{T}) \equiv\left\{\left(\hat{Q}_{N_{k}}^{S_{j}}, \hat{T}_{N_{k}}^{S_{j}}\right)\right\}_{j, k=1, \ldots, L}$ denote the set of all contracts. Define the total number of transfer slots contracted for by $N_{j}$ as $n_{N_{j}}(\hat{Q}) \equiv \sum_{k=1}^{L} \hat{Q}_{S_{k}}^{N_{j}}$. Denote citizens' strategy profile by $a(\cdot, \theta, p, \hat{Q})$ and host states' strategy profile following transfer slot contracting by $p(\hat{Q})$

We look for an equilibrium of the Global Transfer System game, $a^{*}(\cdot, \theta, p, \hat{Q}), p^{*}(\hat{Q})$, and $\hat{Q}^{*}$, in which for all $N_{j}, n_{N_{j}}\left(\hat{Q}^{*}\right)>0$, there is no economic migration, all persecuted people migrate to 
host states in their region of origin (and are distributed evenly across host states), and $\forall j, p_{j}^{*}\left(\hat{Q}^{*}\right)=$ $w$.

First, note that if $N_{k}$ contracts for any transfer slots, no individual southern migrant will want to deviate from the equilibrium by travelling to $N_{k}$ since it would bear the cost $J$ but then be deported to a southern host state under the transfer system. Thus, all refugees migrating to host states in their region of origin in equal numbers to each is indeed Nash equilibrium behavior following $\hat{Q}^{*}$. There is thus no economic migration in equilibrium.

Next, suppose each northern host state $N_{k}$ makes take-it-or-leave-it offers such that $Q_{S_{j}}^{N_{k^{*}}}=\epsilon>$ 0 and $T_{S_{j}}^{N_{k^{*}}}=0 \forall j=1, \ldots, L$. Each southern state $S_{j}$ is indifferent between accepting or rejecting its offers since, given that other southern host states are in equilibrium accepting their contract offers, $S_{j}$ will receive the same number of migrants whether it accepts or rejects its contract offers.

To see whether northern host states have any incentive to deviate, suppose host state $N_{j}$ instead offered contracts that result in no contracted for transfer slots. It would then become more attractive to southern migrants, and all southern migrants with $\theta_{i} \in\{s, \emptyset\}$ would migrate to $N_{j}$, and only those with $e_{i}=s$ would be admitted. This would lower $N_{j}$ 's payoff, as it would be hosting more migrants but receive no altruistic benefit relative to the equilibrium (in which all refugees are hosted). Thus, this is not a profitable deviation. Note that each northern host state $N_{j}$ is indifferent between any $\hat{Q}$ such that $n_{N_{j}}(\hat{Q})>0$ since migrant behavior is the same following any such choices. And clearly $N_{j}$ would be made worse off by choosing any $T_{S_{k}}^{N_{j}}>0$.

Now consider host states' choices of standard of proof. Host states' payoffs in equilibrium are

$$
U_{j}\left(a^{*}(\cdot, \theta, \hat{Q}, p), p^{*}, \hat{Q}^{*}, \hat{T}^{*}\right)=2 \lambda \beta P-B(\lambda / L)
$$

If any host state deviated to $p_{j}=s$, it would receive no uninformed refugees or informed refugees with $e_{i}=w$ but would bear the shading cost $K$. It's payoff would be:

$$
U_{j}\left(a^{*}(\cdot, \theta, \hat{Q}, p), p^{*}, \hat{Q}^{*}, \hat{T}^{*}\right)=2 \lambda \beta P-B\left(\gamma \pi^{R} \lambda / L\right)-K
$$

This will not be a profitable deviation if and only if

$$
K>\underline{\mathrm{K}}^{G T S} \equiv B(\lambda / L)-B\left(\gamma \pi^{R} \lambda / L\right)
$$

Comparing $\underline{\mathrm{K}}^{G T S}$ with $\underline{\mathrm{K}}$ (the minimum $K$ in which $p=w$ is a SPE of the baseline Convention game), given in $(14)$, we see that $\underline{\mathrm{K}}^{G T S}<\underline{\mathrm{K}}$.

To see part (2) of the Proposition, note that southern states payoffs under this equilibrium of the Global Transfer System game, given in (33) are less than southern states payoffs in the $p=w$ equilibrium of the baseline Convention game, given in (12). And for $K \geq \underline{K}, p=w$ is an equilibrium of both the Global Transfer System game and the baseline Convention game.

\section{REFERENCES}

Achiron, Marilyn. 2001. A 'Timeless' Treaty Under Attack. Refugees Magazine, 2(123), 4.

Anker, Deborah, Fitzpatrick, Joan, \& Shacknove, Andrew. 1998. Crisis and Cure: A Reply to Hathaway/Neve and Schuck. Harvard Human Rights Journal, 11, 295-310.

Baldauf, Scott, \& Tohid, Owais. 2003. Where Taliban go to find warm beds and recruits. Christian Science Monitor, Dec. 11, p. 1. 
Bubb, Ryan J., \& Rose-Ackerman, Susan. 2007. BITs and Bargains: Strategic aspects of bilateral and multilateral regulation of foreign investment. International Review of Law and Economics, 27(3), $291-311$.

Guzman, Andrew. 1998. Why developing countries sign treaties that hurt them: Explaining the popularity of BITs. Virginia Journal of International Law, 38, 643-688.

Hathaway, James C., \& Neve, R. Alexander. 1997. Making International Refugee Law Relevant Again: A Proposal for Collectivized and Solution-Oriented Protection. Harvard Human Rights Journal, 10, 115-2211.

Keely, Charles B., \& Russell, Sharon Stanton. 1994. Responses of Industrial Countries to Asylum Seekers. Journal of International Affairs, 47, 399-417.

Kralev, Nicholas. 2007. U.S. to ship refugees half a world away; Washington, Canberra say move isn't a 'swap'. The Washington Times, April 19, p. A17.

Moore, Molly. 2001. The Taliban's Deadly Rise to Power; From Refugee Camp Radicals to Rulers of Afghanistan, Group Prospered With Pakistan's Patronage. The Washington Post, Sept. 16, A14.

Neumayer, Eric. 2005. Asylum Recognition Rates in Western Europe: Their Determinants, Variation, and Lack of Convergence. Journal of Conflict Resolution, 49(February), 43-66.

Polgreen, Lydia. 2007. Resolving Crisis in Congo Hinges on Foreign Forces. The New York Times, Dec. 19, p. A14.

Raustiala, Kal, \& Slaughter, Anne-Marie. 2002. International Law, International Relations, and Compliance. Page 538 of: Carlsnaes, Walter, Risse, Thomas, \& Simmons, Beth A. (eds), Handbook of International Relations. Thousand Oaks.

Schuck, Peter. 1997. Refugee Buden Sharing: A Modest Proposal. Yale Journal of International Law, 22, 243-297.

United Nations High Commissioner for Refugees. 1995. The State of the World's Refugees 1995: In search of solutions.

United Nations High Commissioner for Refugees. 2005. 2005 Global Refugee Trends.

United Nations High Commissioner for Refugees. 2006. The State of the World's Refugees 2006: Human displacement in the new millennium. 